\title{
RULA Analysis of Work-Related Disorder among Packaging Industry Worker Using Digital Human Modeling (DHM)
}

\author{
Mohamad, D., Deros, B.M., Ismail, A.R., Daruis, D.D.I. and Sukadarin, E.H. \\ Department of Mechanical and Materials Engineering \\ Faculty of Engineering and Built Environment \\ Universiti Kebangsaan Malaysia \\ darliana_mohamad@yahoo.com
}

Keywords: Ergonomics, Material handling, RULA Analysis, WMSD, Posture, CATIA, DHM

\begin{abstract}
Musculoskeletal disorder (WMSDs) is the common health problems for the industrial workers. This health problem can contribute to long term effect on the production performance. The objective of this study is to analyze the posture of industrial worker in packaging industry using the RULA assessment in CATIA P3 V5R14 software. The working posture was reconstructed and developed in the CATIA P3 V5R14 software and then RULA assessment was conducted. From the RULA analysis, several awkward postures were detected to be high in risk factors. The postures in risk are postures 1,2 and 5 which mainly involve lifting heavy product and excessive bending. As a conclusion the RULA assessment was able to detect the problematic postures and further improvement can be conducted to avoid discomfort or further health complication.
\end{abstract}

\section{Introduction}

Industrial workers are easier to be exposed to discomfort and pain at work. The occupational risk factors are the biggest factors to this health problems and it can be found at any industries [1]. One of the occupational risk factor to the industrial workforce especially the manual material handling workers are the Musculoskeletal Disorder (MSD) [2, 3]. MSDs are able to degrade the health of the workers thus reduce the workers performance in completing their tasks. Several literatures had suggested that the effect of low performance by the workers can have significant economic and social consequences $[4,5,6,7]$. This can be seen by the compensation claims for the employers that are increasing which may overburden the health system $[8,9]$. One of the major reasons for sick leave and work injuries in industry is due to the inefficient of production ergonomics. Moreover, manufacturing companies had lost a huge amount of money in their resource budget to support the staff replacement and rehabilitation. Reports from many researchers had stated that production interruption and companies' inefficiency may be caused by the high staff turnover and sick leave $[11,12,13]$. Because of this downside, it is important to ensure the health of the workers and their postures is one of the factors that need to be considered closely in running certain work task.

A basic analysis of a work task can depend on questionnaires, interviews and video analysis. In addition, numerous measurements commonly known as assessment method can be used for physical risk assessment of job activities, usually specific to a body part or a type of activity. There are various ergonomic assessment method of manual tasks exist in the market. For example are the RULA, REBA, OWAS, LUBA, QEC, PATH and PEO method [14, 15, 3]. Rapid Upper Limb Assessment (RULA) index is one of the most cited and commonly used tools for evaluating ergonomic risk of work-related MSDs $[15,16]$. RULA is a subjective observation method for posture analysis that focuses on the upper part of the body with the particular attention to the neck, trunk and upper limbs $[17,18,15]$.

Observational methods based on videotaped work task sequences to analyze various kinds of manual tasks with certain software are widely used nowadays because of its practicality and affordability $[19,15]$. When designing a new task, another option is to use digital human models 
(DHM) for ergonomic analysis because by using DHM it is possible to study, analyses and visualize the movement or posture in a user friendly three dimensional graphical interface. This technology also allows designer or an ergonomist to integrate the ergonomic consideration on human subject without the need for direct measurement in the early stage of design [3, 10]. Examples of DHM software packages used for ergonomic assessment are Pro/ENGINEER Manikin Analysis, SAMMIE, JACK, CATIA-HUMAN Design and Analysis tools, RAMSIS and SANTOS [3].

Through this study, CATIA software is chosen for RULA assessment method in order to analyze the posture of the selected worker. As for this study, the selected worker is from the packaging department as his job physical characteristics frequently associated with WMSD risk factors that are include repetitive motion patterns, heavy lifting, forceful manual exertions or prolonged static postures [3]. Thus, the objective of this study is to analyze the posture of industrial worker in packaging industry using the RULA assessment in CATIA P3 V5R14 software. Several studies shown that the outcomes of DHM usage in postural analysis using different tools are fairly accurate [10].

\section{Methodology}

This study was conducted at one of the packaging industry in Klang Valley area. The chosen subject is from the packaging department and the scope of work of the department is to transfer their product into its packaging box and seal it. A simple subjective rating form was given to the subject to be completed in order to evaluate the posture discomfort experienced. Next, the subject was required to conduct his working cycle as usual and the process was recorded through a video recorder. The postures of the working cycle were recorded from the Mid-Sagittal plane view. Several postures from the subject working cycle then are chosen and replicate into a manikin in the CATIA V5R14 software. Later, the RULA analysis was performed on the manikin with exact replication to assess the subject's posture level of discomfort.

\section{Result and Discussion}

From the simple subjective evaluation and interview, it is shown that the subject is clearly experiencing posture discomfort during work. Five postures from the subject working cycle were recorded. The results of RULA analysis are shown in Table 1 for every postures involved. This analysis also shows the body segments that are having problems.

Table 1 Actual working postures and its RULA Analysis in CATIA Software

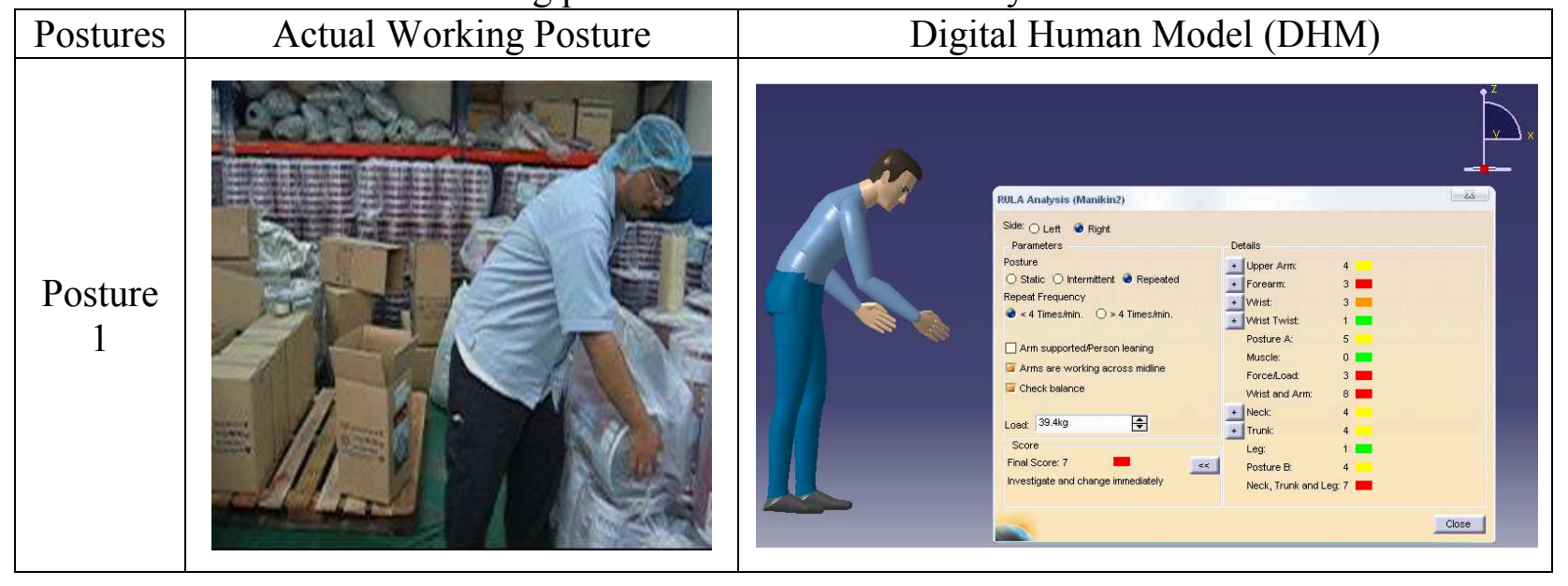




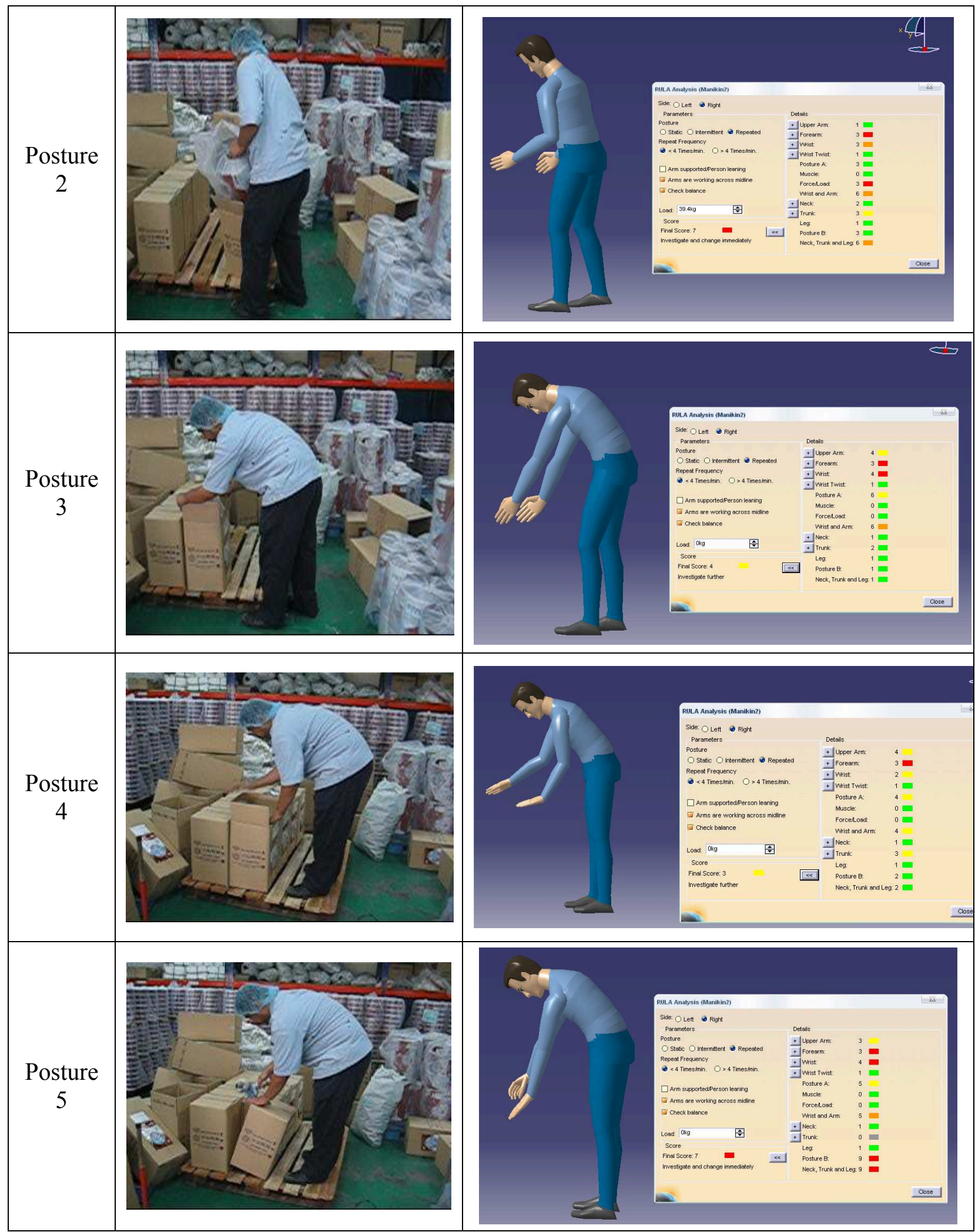

From Table 1, posture 1 is the first step in the working cycle which is to lift a $39.4 \mathrm{~kg}$ load of product from its original place. Product is lift by manual handling without any robot or machine assistance. From RULA analysis, it shows that the posture level is 7 and red in colour. This means that investigation and changes are required immediately. The problem parts are detected around the forearm, upper arm, wrist and trunk. Problem is also detected from the load carried by the subject 
Posture 2 is the working condition where the subject is putting the product into the packaging box on the pallet. At this condition, the load of the product has to be fully supported by the subject. Subject has to bend down a little at this point to balance the product into the box. RULA analysis for posture 2 shows that the posture level is 7 and red in colour. This means that investigation and changes are required immediately. The problem parts are detected around the forearm, upper arm, and wrist. Problem also detected from the load carried by the subject.

Posture 3 is when subject is adjusting the position of the packaging box on the pallet. The product is fully inside the packaging box. RULA analysis of posture 3 show the posture level is 4 and yellow in colour. This indicates that further investigation is needed and changes may be required. Result score shows that posture is in good condition and further investigation is needed for any changes.

During posture 4, subject is trying to close the packaging box lid. Subject has to stand on the pallet to do this job therefore the subject required to bend more to complete the task. From RULA analysis, it can be seen that the posture level is 3 and yellow in colour. This indicates that further investigation is needed and changes may be required. Result score shows that posture is in good condition and further investigation is needed for any changes.

Posture 5 is when subject starting to bind the packaging box with cellophane tape. At this point subject has to hold the handle of the cellophane tape at his right hand. RULA analysis shows that the posture level is 7 and red in colour equal to posture 1 and 2 . This means that investigation and changes are required immediately. The problem parts are detected around the forearm, wrist and posture $\mathrm{B}$.

Overall Analysis. The RULA analysis results from all five postures involved are summarized and shown in Table 2.

Table 2 RULA analysis result for every posture

\begin{tabular}{|c|c|c|c|}
\hline Posture & Level & Colour & Statement \\
\hline 1 & 7 & & Investigate and Change Immediately \\
\hline 2 & 7 & & Investigate and Change Immediately \\
\hline 3 & 4 & & Investigate Further \\
\hline 4 & 3 & & Investigate Further \\
\hline 5 & 7 & & Investigate and Change Immediately \\
\hline
\end{tabular}

From the finding of postural analysis using the RULA method shows that only posture 1, posture 2 and posture 3 are hazardous; therefore, these posture need to be investigate and change immediately. Meanwhile, the other two posture that are posture 3 and posture 4 are still acceptable but need to be investigate further whether the working posture are needed to be change or not in near future.

After the changes is done in the future, the production rate where subject is working is expected to increase as shown from the studies done by Vink et al. [13] which stated that if improvement is done on the workstation for ergonomic reason the production rate will be increased. But, the value of the productivity cannot be known its exact value because of limited information from company. Products that the company produced is for batch production. Variation of product is high and the exact value of production rate cannot be measured clearly. 
Several recommendation that the company can apply in future in order to ensure workers comfort are to use the manipulator arm even for handling a lower load products. Repetitive works can affect the workers' health even though the load is small. The workstation renovation also can ensure a good and comfortable working environment for example by constructing a conveyor belts.

Besides that, a construction of a platform around $37 \mathrm{~cm}$ high can lower the distance height for the subject to insert the product in the packaging box (Figure 1). This improvement can reduce the discomfort problems for subject.

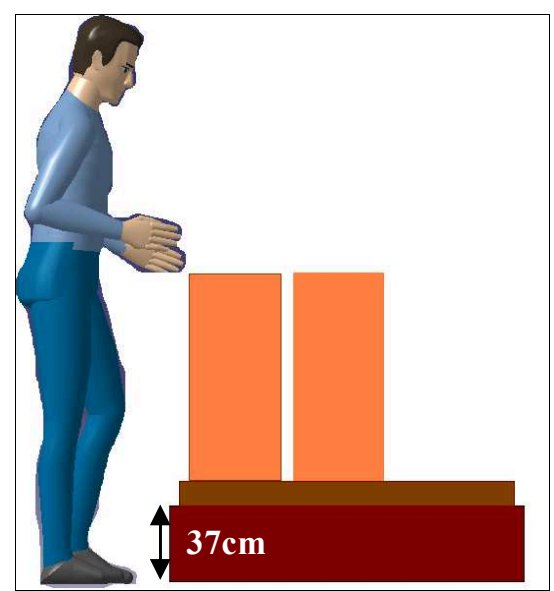

Figure 1 Improvement platform

However, there are certain limitations in this study using the RULA analysis because it only assessed the upper part of the body postures. For obtaining analysis result that are more throughout and extensive, several postural analysis method for whole body assessment is suggested such as the Rapid Entire Body Assessment (REBA), Ovako working posture assessment system (OWAS), Workplace ergonomics risk assessment (WERA), and posture, activity, tools and handling (PATH) method. But the reason RULA assessment is chosen as the postural analysis method in this study is due to the working cycle of the selected subjects mainly involved the movement of the upper extremities.

\section{Conclusion}

It can be concluded that problematic posture could be detected using RULA assessment in CATIA P3 V5R14. From the findings, it shows that further improvement need to be conducted on the manual material handling at the department to avoid discomfort or further health complication.

\section{References}

[1] Halim, I., Omar, A.R. and Saad, N.H. 2005. Ergonomic Assessment to Identify Occupational Risk Factor in Metal Stamping Industry. NAME 05.

[2] Hu, B., Ma, L., Zhang, W., Salvendy, G., Chablat, D., \& Bennis, F. (2011). Predicting realworld ergonomic measurements by simulation in a virtual environment. International Journal of Industrial Ergonomics, 41(1), 64-71.

[3] De Magistris, G., Micaelli, A., Evrard, P., Andriot, C., Savin, J., Gaudez, C., \& Marsot, J. (2013). Dynamic control of DHM for ergonomic assessments. International Journal of Industrial Ergonomics, 43(2), 170-180. 
[4] Aptel, M., Aublet-Cuvelier, A., Cnockaert, J.C., 2002. Work-related musculoskeletal disorders of the upper limb. Joint Bone Spine 69 (6), 546-555.

[5] Taieb-Maimon, M., Cwikel, J., Shapira, B., \& Orenstein, I. (2012). The effectiveness of a training method using self-modelling webcam photos for reducing musculoskeletal risk among office workers using computers. Applied ergonomics, 43(2), 376-85.

[6] Morse, T.F., Dillon, C.,Warren, N., Levenstein, C.,Warren, A., 1998. The economic and social consequences of work-related musculoskeletal disorders: the Con- necticut Upper-Extremity Surveillance Project (CUSP). Int. J. Occup. Environ. Health 4 (4), 209e216.

[7] Punnett, L., Wegman, D.H., 2004. Work-related musculoskeletal disorders: the epidemiologic evidence and the debate. J. Electromyogr. Kinesiol. 14 (1), $13 \mathrm{e} 23$.

[8] Badley, E.M., Rasooly, I.,Webster, G.K., 1994. Relative importance of musculoskeletal disorders as a cause of chronic health problems, disability, and health care utilization: findings from the 1990 Ontario Health Survey. J. Rheumatol. 21 (3).

[9] Chiasson, M.-È., Imbeau, D., Aubry, K., \& Delisle, A. (2012). Comparing the results of eight methods used to evaluate risk factors associated with musculoskeletal disorders. International Journal of Industrial Ergonomics, 42(5), 478-488. doi:10.1016/j.ergon.2012.07.003

[10] Lämkull, D., \& Hanson, L. (2009). A comparative study of digital human modelling simulation results and their outcomes in reality: A case study within manual assembly of automobiles. International Journal of Industrial Ergonomics, 39(2), 428-441.

[11] Hendrick, H.W., 1996. The Ergonomics of Economics is the Economics of Ergo- nomics. Human Factors and Ergonomics Society, Annual Meeting. University of Southern California, USA.

[12] Oxenburgh, M., Marlow, P., Oxenburgh, A., 2004. Increasing Productivity through Health and Safety: The Financial Returns from a Safe Working Environment. Taylor\& Francis, ISBN 0-41524331-9.

[13] Vink, P., Koningsveld, E.A.P., and Molenbroek, J.F. 2006. Positive Outcomes Of Participatory Ergonomics In Terms Of Greater Comfort and Higher Productivity. Applied Ergonomics 37, 537546.

[14] Andreoni, G., Mazzola, M., Ciani, O., Zambetti, M., Romero, M., Costa, F., Preatoni, E., 2009. Method for movement and gesture assessment (MMGA) in ergonomics. In: International Conference on Digital Human Modeling, San Diego, CA, USA, 591-598. 
[15] Vignais, N., Miezal, M., Bleser, G., Mura, K., Gorecky, D., \& Marin, F. (2013). Innovative system for real-time ergonomic feedback in industrial manufacturing. Applied ergonomics, 44(4), 566-74.

[16] Meksawi, S., Tangtrakulwanich, B., \& Chongsuvivatwong, V. (2012). Musculoskeletal problems and ergonomic risk assessment in rubber tappers: A community-based study in southern Thailand. International Journal of Industrial Ergonomics, 42(1), 129-135.

[17] McAtamney, L., Corlett, E.N., 1993. RULA e a survey method for the investigation of workrelated upper limb disorders. Appl. Ergon. 24, 91e99.

[18] Dockrell, S., O’Grady, E., Bennett, K., Mullarkey, C., Mc Connell, R., Ruddy, R., Twomey, S., et al. (2012). An investigation of the reliability of Rapid Upper Limb Assessment (RULA) as a method of assessment of children's computing posture. Applied ergonomics, 43(3), 632-6.

[19] David, G.C., 2005. Ergonomic methods for assessing exposure to risk factors for work-related musculoskeletal disorders. Occup. Med-Oxford 55, 190-199. 